\title{
Magnetic storm effects at equatorial electrojet stations
}

\author{
R. G. Rastogi ${ }^{1,2}$ \\ ${ }^{1}$ Physical Research Laboratory, Ahmedabad 380009, India \\ ${ }^{2}$ Department of Physics, Gujarat University, Ahmedabad 380009, India
}

(Received September 9, 2003; Revised October 31, 2005; Accepted November 1, 2005; Online published May 12, 2006)

\begin{abstract}
It is shown that there are distinctly two different mechanisms for the interaction of solar wind with the earth's magnetosphere to produce electric field in the ionospheric heights at low and middle latitudes. A persistent or slowly varying southward Interplanetary magnetic field i.e. negative $I M F-B_{z}$ generates dawn to dusk electric field at polar latitudes and a westward (dusk to dawn) electric field at dayside electrojet region which is anti-Sq in direction. A rapid increase of $\mathrm{IMF}_{\mathrm{B}} \mathrm{B}_{\mathrm{z}}$ (northward turning) imposes a westward (dusk to dawn) electric field at all latitudes of the dayside hemisphere. The process involved is the imposition of $-\mathrm{V} \times \mathrm{B}_{\mathrm{z}}$ electric field at the magnetosphere transmitted instantaneously to the magnetic equator through the polar latitudes. The changes in the $\mathrm{H}$ field at ground are largest at stations close to the magnetic equator and the midday longitudes. During magnetic storms, associated with the southward IMF-B $\mathrm{B}_{\mathrm{z}}$, there are definite enhancements in the decrease of $\mathrm{H}$ field at the dayside equatorial electrojet stations. These changes may be coincident with the development of auroral or magnetospheric ring currents. These enhancements may be observed during the main phase as well as during the recovery phase of the magnetic storm, but the essential condition is that the IMF- $\mathrm{B}_{\mathrm{z}}$ has to be steadily significant southward. Sometimes during the storm period abnormally large changes in $\mathrm{H}$ field at day side equatorial electrojet regions are observed associated with large sudden changes in IMF- $\mathrm{B}_{\mathrm{z}}$ following the second mechanism of solar wind magnetospheric interaction. Thus the equatorial magnetic storm effects are due to combined effects of disturbance ring current, slow and steady IMF- $\mathrm{B}_{\mathrm{z}}$ as well as due to sudden large changes in IMF-B
\end{abstract}

Key words: Magnetic storms, equatorial electrojet, Interplanetary Magnetic Field.

\section{Introduction}

1.1 Sq current system and equatorial normal and counter electrojets

The daily variations of the Earth's magnetic field was suggested by Stewart (1882) as due to the movement of the conducting upper atmosphere across the vertical component of the earth's magnetic field arising by the regular atmospheric motions caused by the solar heating of the atmosphere. Chapman (1919) computed the global ionospheric current system and attributed the regular atmospheric movements as mainly due to the lunar tidal effects. Egedal (1947) discovered an enhancement of the daily variation of $\mathrm{H}$ within a narrow belt over the magnetic equator. Chapman (1951) explained the phenomenon as due to a strong eastward flowing band of current in the E region of the ionosphere within $5^{\circ}$ over the magnetic equator and named it Equatorial Electrojet (EEJ). Later, it was shown that the unique situation of the orthogonality of the electric and magnetic fields and the different vertical profiles of the mobilities of the ions and electrons in the $\mathrm{E}$ region, results in an abnormal increase of the electric conductivity over the magnetic equator (Cowling and Borger, 1948). This causes a larger current over the equator with the same electric field as at other low latitudes outside the EEJ (Baker and Martyn,

Copyright (c) The Society of Geomagnetism and Earth, Planetary and Space Sciences (SGEPSS); The Seismological Society of Japan; The Volcanological Society of Japan; The Geodetic Society of Japan; The Japanese Society for Planetary Sciences; TERRAPUB.
1953).

Bartels and Johnston (1940) showed abnormally large amplitudes of lunar tidal oscillation in $\mathrm{H}$ at Huancayo, such that on certain days the $\mathrm{H}$ field decreased below the nighttime base level. Gouin and Mayaud (1967) described occasional negative $\Delta \mathrm{H}$ during the daytime hours at AddisAbaba and suggested it as due to Counter Electrojet (CEJ) current flowing westward. Rastogi (1974) described the latitudinal, seasonal and solar cycle variations of CEJ at all available equatorial stations round the world. Later, Rastogi (1975) found cases when there was only a depression of $\Delta H$ at Trivandrum, with the minimum value of $\mathrm{H}$ being always above the nighttime base value, but the $\Delta \mathrm{H}$ at Trivandrum minus $\Delta \mathrm{H}$ at Alibag was definitely negative and called it as partial counter electrojet. Fambitakoye et al. (1973) suggested the reversals of the regular latitudinal variations SR of $\mathrm{H}$ and $\mathrm{Z}$ fields across the dip equator during the events. These partial counter electrojet events were explained on the basis of two currents in the equatorial ionosphere at the same time. An eastward current flows at an altitude close to $107 \mathrm{~km}$ corresponding to the latitude of the peak E layer electron density associated with the global atmospheric dynamo Sq current system. Another current flows at the base of the E region, $100 \mathrm{~km}$ or less, occasionally to eastward and sometimes to westward direction associated with the pure equatorial electrojet. The source of this additional current is to be sought in the electric field transmitted from various magnetospheric processes. Carter et al. (1976) did 


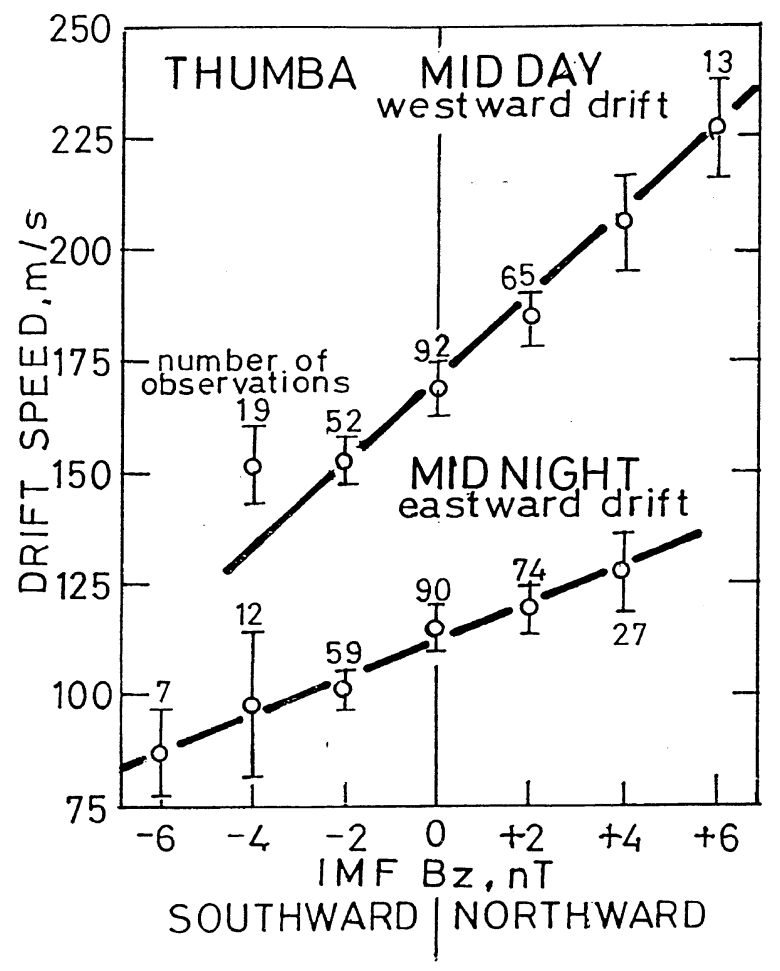

Fig. 1. The westward ionospheric drifts during midday hours and the eastward ionospheric drifts during midnight hours at Thumba, India as a function of the Interplanetary magnetic Field component normal to the ecliptic, IMF-B $\mathrm{z}$, (after Rastogi and Chandra, 1974).

observe simultaneous two opposite flowing current at different altitudes over the electrojet region during magnetically disturbed conditions in their oblique VHF forward scatter experiment in African longitudes.

\subsection{Equatorial ionospheric drifts}

The drift of ionospheric irregularities in the $\mathrm{E}$ region of the ionosphere over the magnetic equator is another manifestation of the EEJ phenomenon. Extensive hourly measurements of drifts by spaced receiver method were made at Thumba, near magnetic equator in India during 1963-1969 that provided more than 30,000 observations unparalleled anywhere in the world.

A regular pattern of the daily variation of the drifts, being westward during the daytime and eastward during the nighttime, reversing suddenly within a few minutes was observed (Deshpande and Rastogi, 1968). Daily and seasonal variations of the drifts were shown to be similar to the corresponding variations of the $\mathrm{H}$ field at Trivandrum (Chandra et al., 1971). A linear correlation was shown between the midday values of the drift speed and the daily ranges of the $\mathrm{H}$ field at Trivandrum. A higher correlation coefficient was found when the differences of the range at Trivandrum and Alibag were taken as a measure of the electrojet strength rather than the total range of $\mathrm{H}$ at Trivandrum alone (Chandra et al., 1971). This suggested that the total ionospheric current over the magnetic equator is the combination of the Sq current system and the narrow band of electrojet current.

Misra et al. (1971) studied the solar cycle variation of drift at Thumba and the drift was found to be practically independent of the solar cycle. It has been heartening that these conclusions derived from a simple comparatively inexpensive experiment were later confirmed by the Doppler Shift observations of $50 \mathrm{MHz}$ backscatter echoes at the massive powerful Radar at Jicamarca in Peru (Balsley, 1973; Fejer et al., 1979).

Rastogi et al. (1971a) showed that the day time decreases of the $\mathrm{H}$ field below the night level (counter electrojet events) were associated with sudden disappearances of the equatorial Es layer and were concurrent with the reversal of the ionospheric drifts i.e. with the reversal of the ionospheric electric field over the magnetic equator to westward direction. The studies of simultaneous ionospheric and magnetic data from Kodaikanal indicated a decrease of daily range of $\mathrm{H}$ and an increase of the midday $\mathrm{f}_{\mathrm{o}} \mathrm{F}_{2}$ with increasing magnetic disturbances, suggesting the weakening of the equatorial electrojet with increasing geomagnetic Kp index (Rastogi et al., 1972). But it was the ionospheric drift data at Thumba, which showed that the drift speed during the midday hours in the $\mathrm{E}$ and $\mathrm{F}$ regions of the ionosphere decreased progressively with increasing Kp index (Rastogi et al., 1971b). Patel and Chandra (1982) showed that with the increasing $\mathrm{Kp}$ index, the drift speed at stations within the $\mathrm{Sq}$ focus latitude and the equator, Thumba, Tiruchirapalli and Ahmedabad decreased steadily. However at station north of the Sq focus latitude, Yamagawa and Sibzimir, the daytime drift speed (eastward) increased steadily with the increase of Kp index. This suggests that the westward electric fields imposed on the ionosphere during magnetic disturbances are of global nature occurring at equatorial, low, middle and sub-auroral latitudes.

Using the Modified Range Time Intensity (MRTI) records from VHF backscatter radar at Jicamarca, Rastogi et al. (1977) showed that the reversal of the electrojet current along $75^{\circ} \mathrm{W}$ sector is very precisely identified by the index $\Delta \mathrm{H}$ at Huancayo minus $\Delta \mathrm{H}$ at Fuquene crossing the zero line. Later Rastogi and Patil (1986) showed that the Doppler shift of $50 \mathrm{MHz}$ back-scatter echoes at Thumba are very precisely correlated with $\Delta \mathrm{H}$ Trivandrum minus $\Delta \mathrm{H}$ at Alibag.

Thus, in all further discussions $\Delta \mathrm{H}$ (TRD) minus $\Delta \mathrm{H}$ (ABG) or briefly $\Delta \mathrm{H}$ (TRD-ABG) is taken to represent the equatorial electrojet component of the ionospheric current over the dip equator in India. Similarly for American sector $\Delta \mathrm{H}$ (HUA-FUQ) is taken as index of equatorial electrojet current.

\subsection{Equatorial electric field and Interplanetary Mag- netic Field}

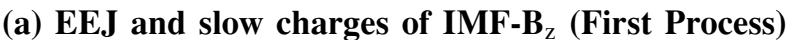
The large data set of ionospheric drifts at Thumba enabled Rastogi and Chandra (1974) to identify a direct correlation between the equatorial ionospheric drifts and the IMF- $\mathrm{B}_{\mathrm{Z}}$ component. In Fig. 1 are shown the daily values of midday and midnight drift speed as a function of the corresponding hourly mean value of IMF- $B_{z}$. It has to be remembered that as a consequence of $\mathrm{Sq}$ electric field, the normal daytime drifts are westward and nighttime drifts are eastward. It can be seen that the decreasing of $I M F-B_{z}$ component causes a steady decrease of the daytime or the nighttime drifts or electric field. Thus it is important to note that long period fluctuations of the magnitude of IMF normal to the 


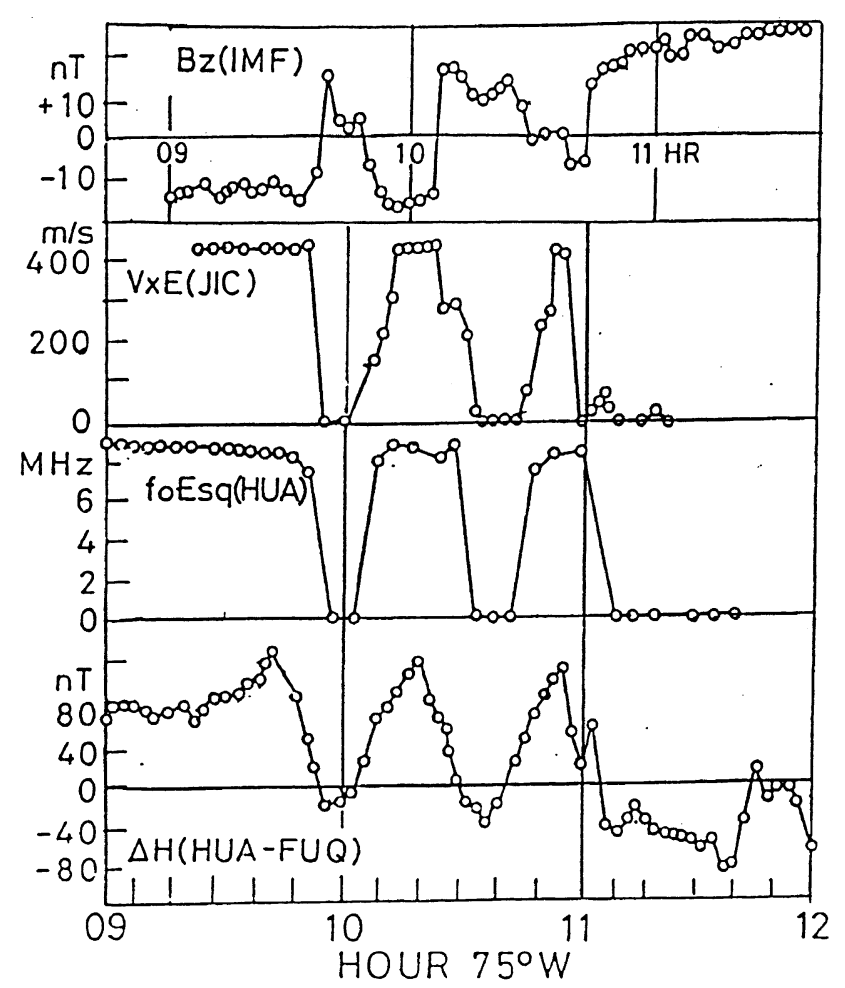

Fig. 2. Large fluctuations in the equatorial electrojet in American sector, $\Delta \mathrm{H}$ (HUA-FAQ) of a period of about half an hour, the disappearance of Esq at Huancayo ionograms during intervals of negative electrojet, decrease of (and probably reversal) of $\mathrm{E}$ region horizontal electron drifts at Jicamarca all associated with the northward turning of IMF $\mathrm{B}_{\mathrm{z}}$ component.

ecliptic (IMF $B_{z}$ ) with a period of the order of few hours are positively correlated with the $\mathrm{Sq}$ electric field at low latitudes and these charges of $\mathrm{B}_{\mathrm{z}}$ are in phase with the $\mathrm{Sq}$ electric field.

(b) Quick changes of IMF $B_{z}$ (Second Process) Rastogi and Patel (1975) noted that large and quick changes of the latitude $(\theta)$ of IMF from its southward to northward direction are associated with the disappearance of Esq at Huancayo, reversal of $E$ region horizontal and $F$ region vertical electron drifts during the day time hours at Jicamarca suggesting an imposition of a westward ionospheric electric field opposite to the direction of normal Sq field. They showed an example of a remarkable northward turning of latitude $\operatorname{IMF}(\theta)$, the reversal of $E$ region horizontal drift and $\mathrm{F}$ region vertical drift at Jicamarca and a positive pulse in $\mathrm{H}$ field at Huancayo during the local night time hours on 2-3 July 1968. This event was so strong that the imposed eastward electric field could produce significant positive pulse of $\Delta \mathrm{H}$ at Huancayo even during the nighttime hour. The change in equatorial electric field due to quick changes of $B_{z}$ is again anti-Sq in nature.

In Fig. 2(a) are shown an example of remarkable quick northward turnings of $\mathrm{B}_{\mathrm{z}}$ at 0933,1003 and $1040 \mathrm{hr}\left(75^{\circ} \mathrm{W}\right)$ on 13 December 1966. Each of these events was associated with immediate decrease of the equatorial electrojet, $\Delta \mathrm{H}$ (HUA-FUQ). The disappearance of Esq at Huncayo and the decreased (and probably reversal) E region horizontal electron drift at Huancayo. No eastward E region drifts were noted during CEJ events because there are no E region irregularities to backscatter VHF radar signals when $\Delta H$ (HUA-FUQ) is below the zero level. The changes in $B_{z}$ were noticed earlier at satellite (Explorer 33) than at ground because the satellite was in the sunward side of the earth at about 40 earth radii.

Thus, it is to be concluded that fast increases of IMF $B_{z}$ (positive) of periods of an hour or so cause an imposition of an anti-Sq electric field over the equatorial ionosphere. The slow fluctuations of IMF- $B_{z}$ with period of few hours cause imposition of electric field over the equator parallel to the Sq electric field.

\subsection{Equatorial electrojet and magnetic disturbance}

The presently accepted morphology of magnetic storms was first identified by Moos (1910) analyzing the geomagnetic field data of Colaba, India for the years 1846 to 1905. The geomagnetic storms observed by ground based magnetometers commonly begin with a sudden increase of the $\mathrm{H}$ field, called Storm Sudden Commencement (SC) followed by an above normal value of $\mathrm{H}$ for few hours denoted as Initial phase, followed by a sudden decrease lasting 4-10 hours called Main phase followed by a Recovery phase lasting 1 to 2 days. Some of the storms have only a gradual commencement. The SC is attributed to the sudden increase of dynamic pressure on the magnetosphere, by the plasma ejected from the Sun after solar flares or by coronal mass ejection. SCs are also considered to be caused by hydromagnetic shocks in the solar wind (Burlaga and Ogilivie, 1969). Initial phase is due to the continued solar wind pressure until Interplanetary Magnetic Field (IMF) turns southward when solar wind magnetic field lines merge with magnetospheric field line and the solar plasma makes entry to earth's magnetic lines of force gets trapped in earth's magnetic field lines and oscillates between high latitudes simultaneously drifting normal to the field lines. The protons drift westward and electrons eastward, causing a westward equatorial ring current at 3-5 earth radii, which decreases the $\mathrm{H}$ field at all low and middle latitudes. The strength of the equatorial ring current is given by a Dst Index first suggested by Sugiura (1964).

Sugiura and Chapman (1960) described the results of an extensive study of storm time variations of H, D and Z components of the geomagnetic field at a large number of stations distributed all over the world. No storm time variations in $\mathrm{H}$ were found at the equatorial stations, represented only by Huancayo. Studying the storm time variations of $\mathrm{H}$ at stations in the Indo-Russian chain, Rastogi (1999) found that the maximum depression of $\mathrm{H}$ field during the main phase showed a maximum over the magnetic equator larger than expected of the Dst index. It was suggested that this is another manifestation of the equatorial electrojet by the imposition of an additional westward electric field in the ionosphere.

Rastogi (1972) showed a close relationship between polar and equatorial disturbances on 26 July 1969 when there was a large decrease of $\mathrm{H}$ at Huancayo between 0900-1100 $\mathrm{hr}$ and a corresponding increase of $\mathrm{H}$ field at Thule and this event was associated with the disappearance of Esq at Huancayo between $0945-1015 \mathrm{hr}$. Thus isolated polar disturbances are closely related to the imposition of a westward electric field over the magnetic equator during the 
Table 1. List of stations used with codes and coordinates.

\begin{tabular}{|c|c|c|c|c|c|c|}
\hline \multirow[t]{2}{*}{ Station } & \multirow[t]{2}{*}{ Code } & \multicolumn{2}{|c|}{ Geog. } & \multicolumn{2}{|c|}{ Geom. } & \multirow{2}{*}{$\begin{array}{r}\text { Dip } \\
{ }^{\circ} \mathrm{N}\end{array}$} \\
\hline & & Lat. ${ }^{\circ} \mathrm{N}$ & Long. ${ }^{\circ} \mathrm{E}$ & Lat. & Long. & \\
\hline Novosobirsk & NVS & 55.0 & 82.9 & 45.2 & 159.4 & 58.3 \\
\hline Tashkent & TKT & 41.3 & 69.1 & 32.7 & 145.9 & 41.0 \\
\hline Ashkhabad & ASK & 38.0 & 58.1 & 30.7 & 134.9 & 36.8 \\
\hline Sabhawala & $\mathrm{SAB}$ & 30.4 & 77.8 & 21.0 & 151.8 & 26.9 \\
\hline Jaipur & JAI & 26.9 & 75.8 & 17.8 & 149.5 & 22.4 \\
\hline Ujjain & UJJ & 23.2 & 75.8 & 14.1 & 149.1 & 18.1 \\
\hline Nagpur & NGP & 21.2 & 79.1 & 11.7 & 151.9 & 12.6 \\
\hline Alibag & $\mathrm{ABG}$ & 18.6 & 72.9 & 9.9 & 145.8 & 12.8 \\
\hline Vishakhapatnam & VSK & 17.6 & 83.3 & 7.8 & 155.5 & 11.6 \\
\hline Hyderbad & HYB & 17.4 & 78.6 & 8.1 & 151.2 & 10.7 \\
\hline Pondicherry & PON & 11.9 & 79.9 & 2.4 & 151.7 & 4.6 \\
\hline Annamalainagar & ANN & 11.4 & 79.5 & 2.0 & 151.7 & 2.8 \\
\hline Kodaikanal & KOD & 10.2 & 77.5 & 1.0 & 149.4 & 1.6 \\
\hline Ettayiapuram & ETT & 9.2 & 78.0 & -0.2 & 149.8 & 0.5 \\
\hline Trivandrum & TRD & 8.5 & 77.0 & -0.7 & 148.7 & -0.3 \\
\hline Fuquene & FUQ & 5.5 & 286.3 & 15.7 & 358.0 & 31.8 \\
\hline Koror & KOR & 7.3 & 134.5 & -1.9 & 306.1 & -0.6 \\
\hline Jarvis & JAR & -0.4 & 200.0 & -0.1 & 271.8 & 2.2 \\
\hline Addis-Ababa & AAE & 9.0 & 38.8 & 5.3 & 111.8 & 0.5 \\
\hline Huancayo & HUA & -12.1 & 284.7 & -1.8 & 356.3 & 1.7 \\
\hline M'Baur & $\mathrm{MBO}$ & 14.4 & 343.0 & 20.1 & 57.5 & 9.1 \\
\hline Dallas & DAL & 33.0 & 263.3 & 42.2 & 331.5 & 62.6 \\
\hline La Quiaea & LQA & -22.1 & 294.4 & -11.9 & 5.9 & -14.8 \\
\hline Pilar & PIL & -31.7 & 296.1 & -21.5 & 7.2 & -31.3 \\
\hline
\end{tabular}

daytime hours. Later similar correspondence between increase of $\mathrm{H}$ field at Thule on 18 March 1958 and 3 September 1958 were shown to be coincident with the decrease of $\mathrm{H}$ at Huancayo associated with disappearance of equatorial Es (Rastogi, 1973a, b).

Kelley et al. (1976) had described the simultaneous measurements of the electric field in the auroral zone near College in Alaska and at the magnetic equator over Jicamarca, Peru during the great storm events of 8-9 August 1972. The electric fields in the auroral region were measured by the balloon-borne detectors and in the equatorial region by the incoherent scatter radar. A general agreement was seen between the two sets of observations. Rastogi (1977) combined these data with the geomagnetic field variations at Huancayo, Fuquene, Trivandrum, Kodaikanal and Alibag together with other disturbance indices AU, AL, AE, ASY, and Dst. The electric field at the equatorial station Jicamarca was shown to have reversed between 07-12 UT (0205 LT) and was preceded by similar changes in the westward electric field in the auroral region. The abnormal changes at the equatorial latitudes in the American zone (in the night time) were shown to be closely associated with the westward electric field in the Indian zone (in the day time) causing a counter-electrojet and the disappearance of Esq (Rastogi, 1989). Recently, Rastogi (2004) has shown that magnetic storms occurring during local midday hours produce much larger decrease of the $\mathrm{H}$ field at equatorial sta- tion Kodaikanal compared to the decrease of $\mathrm{H}$ field at offequatorial low latitude station, Alibag situated in the same longitude sector.

It was decided to study the storm time variations of $\mathrm{H}$ at the stations along Indo-USSR chain in relation to ring current index Dst, Auroral current index AE, solar wind parameters (velocity, speed and density) and interplanetary magnetic field $\left(\mathrm{IMF}-\mathrm{B}_{\mathrm{z}}\right)$. The present paper describes the results of such a study.

\section{Data}

\subsection{Method of analysis and results}

Throughout the paper, the time standard used corresponds to $75^{\circ} \mathrm{E}$ meridian, as most of the stations are situated around $75^{\circ} \mathrm{E}$ geographic longitude. In some cases where data from different longitudes are used in the same diagram, standard time used is universal time (UT). The storm time deviation in $\mathrm{H}, \Delta \mathrm{H}$, is taken as hourly mean value of $\mathrm{H}$ at any hour on a storm day minus the $\mathrm{Sq} \mathrm{H}$ value for the some local time. The variation of this with time is designated as storm time variation of $\mathrm{H}$, or Dst $(\mathrm{H})$ variation. The strength of the equatorial ring current is taken as Dst index suggested by Sugiura (1964). AE is taken as the index of auroral current as first suggested by Davis and Sugiura (1966). The Dst and AE indices for the present analysis were downloaded from the website of WDC2 at Kyoto, Japan. The hourly mean values of $\mathrm{H}$ are taken from year- 
(b)

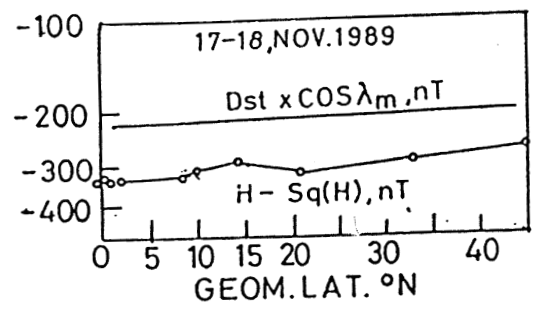

(a)

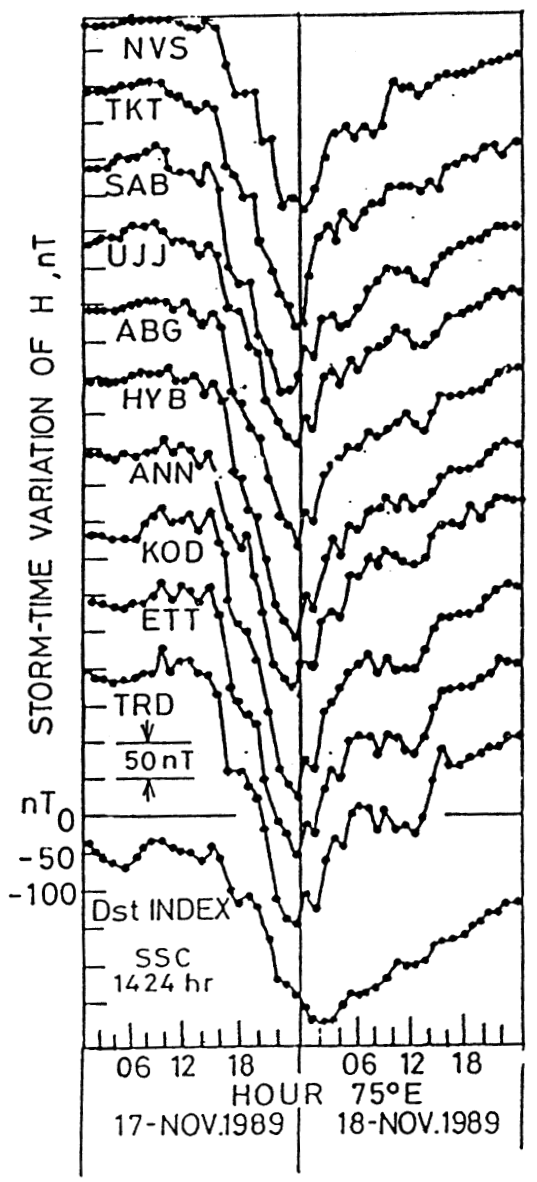

Fig. 3. (a) Storm time variations of $\mathrm{H}$ field at Indo-USSR chain of stations during the storm starting with SC at $1424 \mathrm{hr}$ on 17 November 1989. (b) Latitudinal variations of the minimum Dst index value at different stations at $0030 \mathrm{hr}$ and $1230 \mathrm{hr}$ on 21 February 1992.

books published by the Indian Institute of Geomagnetism, Bombay and National Geophysical Research Institute, Hyderabad or from the data archives at Digital data Centre, Bombay. The list of stations whose data are used together with their codes and other relevant data are given in Table 1. It may be noted that four of these stations, TRD, ETT, KOD and ANN are situated within the equatorial electrojet belt, HYB, ABG, JAI, and UJJ are low latitude stations outside the EEJ belt, SAB is close to the Sq focus latitude. ASK, TKT and NVS are station on the polar side of the Sq focus latitude.

\subsection{Case history of some magnetic storms}

2.2.1 Magnetic storm of 17-18 November 1989 A severe magnetic storm started with SC at $1424 \mathrm{hr}$ on 17 November 1989. The storm time variations of $\mathrm{H}$ at different stations are shown in Fig. 3(a). The main phase onset was at $1530 \mathrm{hr}$. The minimum value of Dst index was $266 \mathrm{nT}$
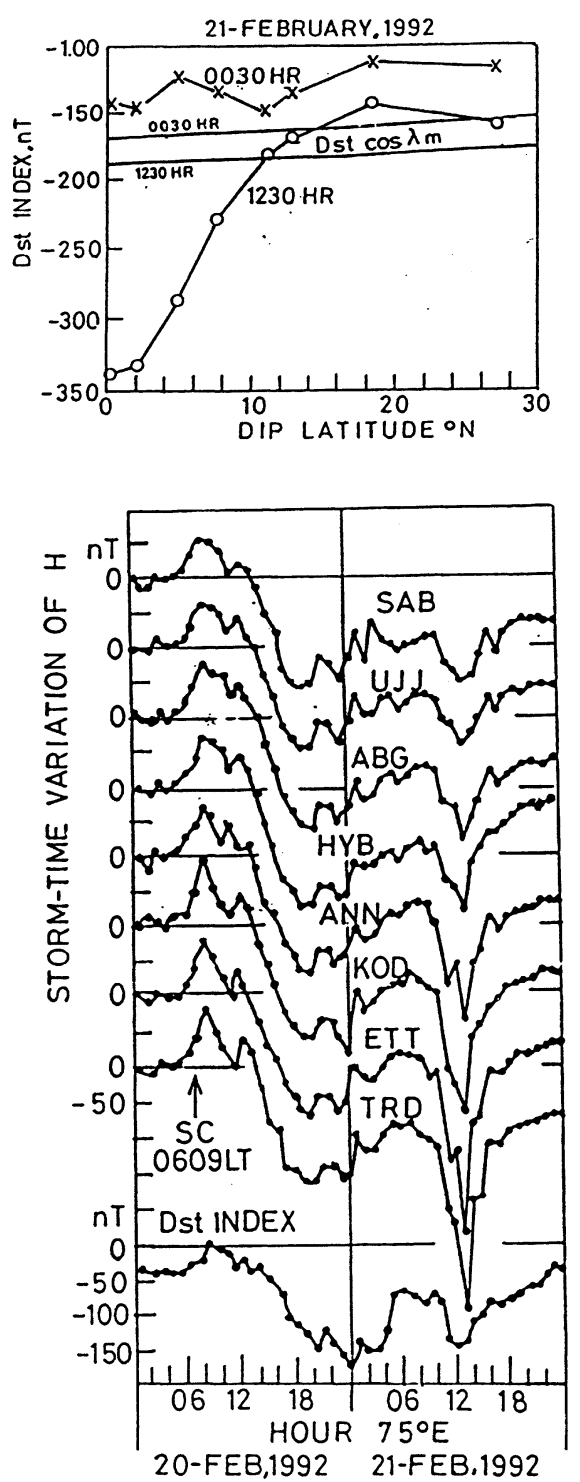

Fig. 4. (a) Storm-time variations of $\mathrm{H}$ field at Indo-USSR chain of stations during the magnetic storm with SC at $0609 \mathrm{hr}$ on 20 February 1992. (b) Latitudinal variations of the minimum $\Delta \mathrm{H}$ at different station at 0030 hr and $1230 \mathrm{hr}$ on 21 February 1992.

at $0230 \mathrm{hr}$ on 18 November. $\Delta \mathrm{H}$ at any station started decreasing at $1530 \mathrm{hr}$ and reached a minimum value around midnight hours. The storm time variations at any of the stations were very similar to each other and similar to the variation of Dst index itself. In Fig. 3(b) are shown the latitudinal variations of minimum value of Dst $(\mathrm{H})$ field at different stations compared with the geomagnetic latitude corrected Dst index. The minimum Dst was around -266 $\mathrm{nT}$. The minimum $\mathrm{H}-\mathrm{Sq}(\mathrm{H})$ values at different stations were around $-300 \mathrm{nT}$ and varied with latitude as expected of the $\cos \lambda \mathrm{m}$ term.

Thus, for storms with its peak depression around local midnight hours, the magnitude of depression of $\mathrm{H}$ at different stations along same longitude sector varied with latitude as the cosine geomagnetic latitude and no abnormal feature were detected at the dip equator stations.

2.2.2 Magnetic storm of 20-21 February 1992 In Fig. 4(a) are shown the storm-time variations of $\mathrm{H}$ at all 


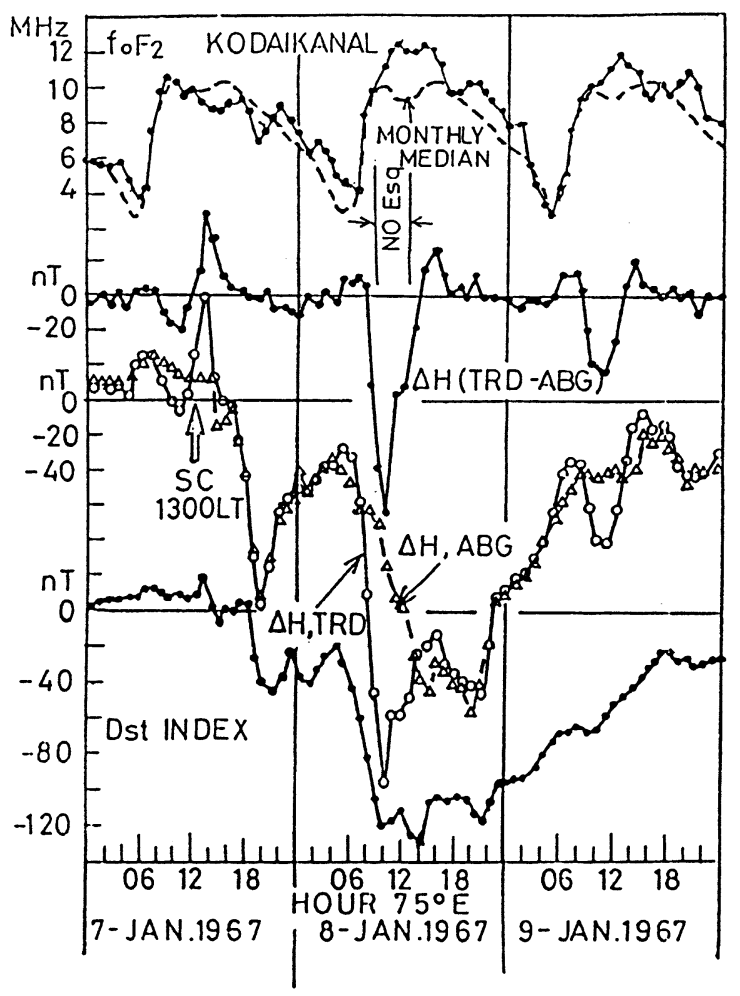

(a)

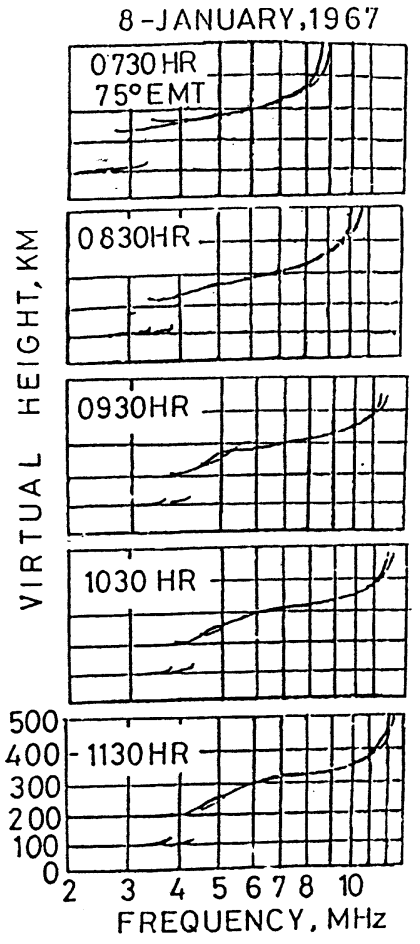

(b)

Fig. 5. (a) Variations of Dst index, storm time variation of $\mathrm{H}$ field at Trivandrum (TRD) at Alibag (ABG) and $\Delta \mathrm{H}$ (TRD-ABG) on 7 to 9 January 1967. (b) Ionograms at Kodaikanal on 8 January 1967 showing the absence of equatorial sporadic E echoes.

Indian stations during the storm on 20-21 February 1992. The SC was at $0609 \mathrm{hr}$ and the Dst index decreased suddenly at $1130 \mathrm{hr}$ reaching a minimum value of $160 \mathrm{nT}$ between 1930-2330 hr after which there was slight recovery. The Dst index decreased very steeply at $1030 \mathrm{hr} 75^{\circ} \mathrm{E}$ on 21 February 1992 reaching a minimum of $-160 \mathrm{nT}$ at $1330 \mathrm{hr}$. The first minimum of Dst around pre-midnight hours was associated with corresponding decrease of $\mathrm{H}$ field at every station. the magnitude of storm decrease was roughly of the same order at any of the stations. The second decrease of Dst around noon on 21 February 1992 was associated with extra-ordinary large decrease of less than $-350 \mathrm{nT}$ at equatorial stations. This midday depression of $\Delta \mathrm{H}$ decreased progressively with increasing distance of the station from the dip equator, indicating a predominant equatorial electrojet effect.

In Fig. 4(b) are shown the latitudinal variations of the storm time decreases of the $\mathrm{H}$ field at $0030 \mathrm{hr}$ and $1230 \mathrm{hr}$ on 21 February 1992. It is seen that the storm decrease at midnight was practically constant with latitude where the same for midday hours showed a steady decrease from $-170 \mathrm{nT}$ at $12^{\circ}$ dip latitude to $-340 \mathrm{nT}$ at the dip equator. This indicates that the storm effects at equatorial latitudes are not entirely due to the magnetospheric ring current but have a significant contribution during the midday hours due to currents in the ionosphere.
2.2.3 Magnetic storm of 7-9 January 1967 A magnetic storm started with SC at $1300 \mathrm{hr}$ on 7 January 1967. Figure 5(a) shows storm time variations of $\mathrm{H}$ at TRD and ABG, $\triangle H$ (TRD-ABG) and $f_{o} F_{2}$ at Kodaikanal. Figure 5(b) shows some ionograms at Kodaikanal on 8 January 1967. The $\mathrm{F}_{2}$ layer critical frequencies on 8 January were $12 \mathrm{MHz}$ compared to the monthly mean value of $9 \mathrm{MHz}$, indicating the absence of usual bite out in the $F$ region due to fountain effect caused by an eastward electric field over the dip equator. Further, no Esq reflections were recorded on the Kodaikanal ionograms between 1000 and $1500 \mathrm{hr}$ again indicating a westward electric field in the ionospheric E region. The IMF parameters were not available on these days but the IMF $B_{z}$ was extraordinarily large negative about -25 $\mathrm{nT}$ around the period of counter electrojet. There was again a small decrease of Dst around noon on 9 January 1967 associated with large decrease of $\Delta H$ at TRD and negative value of $\Delta H$ (TRD-ABG) during the period. During large magnetic storm of 7-9 March 1970, the vertical drifts at Jicamarca had reversed to downward during midday hours and were associated with the counter electrojet event on the magnetogram and the disappearance of Esq on the ionograms at Huancayo (Rastogi, 1973a).

2.2.4 Statistical study of storm time decrease of $\mathbf{H}$ at Trivandrum and Alibag The minimum storm time variations of $\mathrm{H}$ were computed for each magnetic storm between January 1958 to December 1997 at the equatorial 


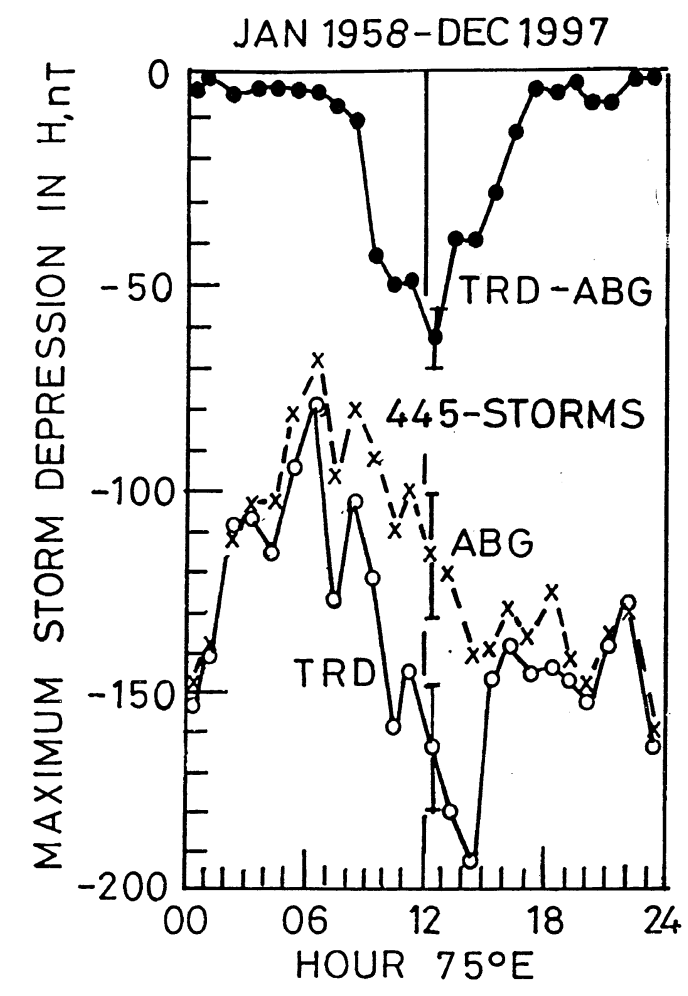

Fig. 6. Hourly means of the maximum storm time depression of $\mathrm{H}$ with respect to the corresponding $\mathrm{Sq} \mathrm{H}$ value for the stations Trivandrum (TRD), Alibag (ABG) and Trivandrum minus Alibag averaged by 445 storms occurring during the period January 1958 to December 1997.

station Trivandrum and at Alibag a low latitude stations outside the electrojet. On few occasions when the data were lost at Trivandrum, it was replaced by the data at neighbouring electrojet station KOD or ETT. A total of 445 storms data were found common to two stations. These data were grouped into each one hourly group and the mean value with standard error was computed. For each storm $\Delta \mathrm{H}$ (TRD) minus $\Delta \mathrm{H}(\mathrm{ABG})$ was also computed and the grouping of hourly data and derivation of hourly mean Dst H (TRD-ABG) was computed. Figure 6 shows the variation with the local time of the parameters mean maximum storm time depressions of $\mathrm{H}$ field at Trivandrum, Alibag and at Trivandrum minus Alibag. At Alibag, $\Delta \mathrm{H}$ has a peak at dawn and a minimum at dusk. At TRD the $\Delta H$ values were almost similar to those at ABG for the nighttime hours. For the daytime hours there was a major minimum around 14 hr unlike that at Alibag. It is interesting to note that $\Delta \mathrm{H}$ (TRD) minus $\triangle \mathrm{H}(\mathrm{ABG})$ is negative for all the hours 0600 to $1800 \mathrm{LT}$ with a prominent minimum at noon.

Thus, it is concluded that the storm time decrease of $\mathrm{H}$ at equatorial station is enhanced at any of the daytime hour with a maximum effect at noon.

\subsection{Solar wind parameters and magnetic storm effects in equatorial electrojet}

2.3.1 Magnetic storm of 26 June 1998 Figure 7 shows the variations of the solar wind parameters and the geomagnetic $\mathrm{H}$ field at Trivandrum and Alibag during the magnetic storm following a SC at $1600 \mathrm{hr}$ on 25 June 1998. The $\mathrm{B}_{\mathrm{z}}$ was strongly northward at the time of SC and even for next eight hours during which Dst index as well as storm

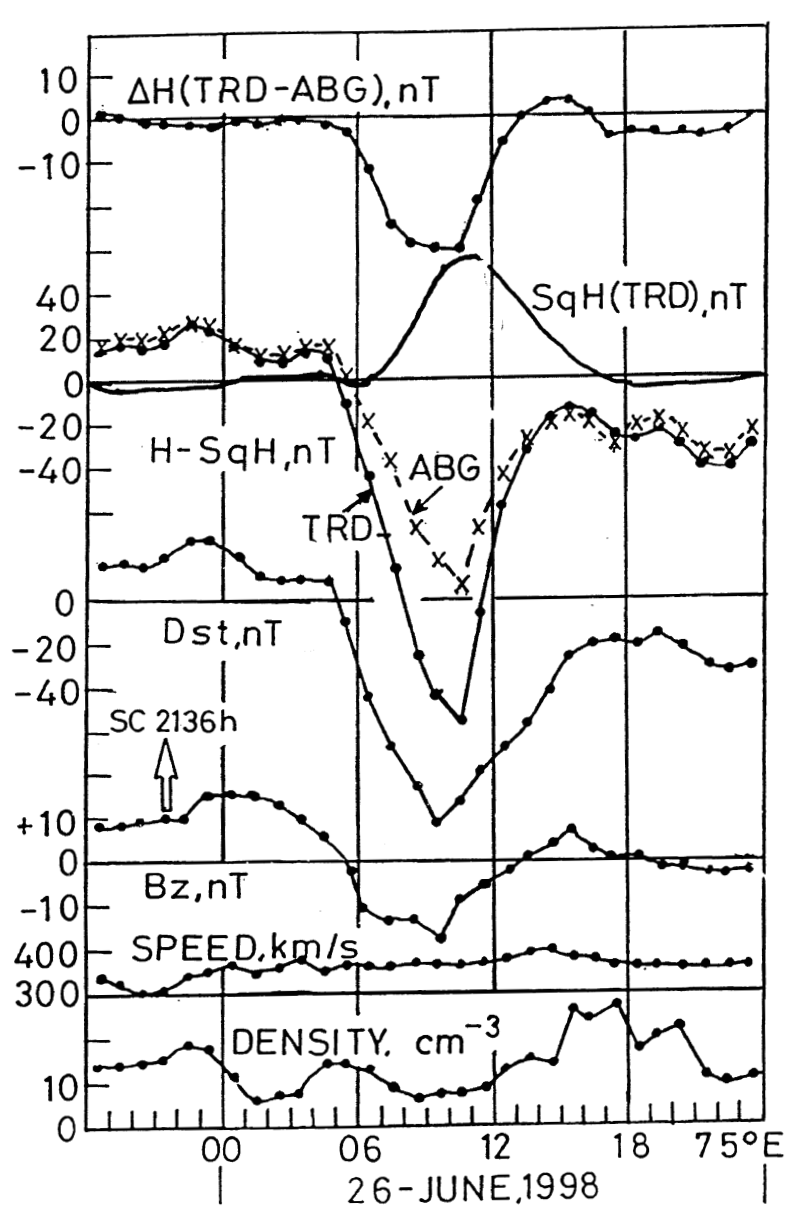

Fig. 7. Variations of solar wind density, speed, IMF $\mathrm{B}_{\mathrm{z}}$ component and Dst index compared with storm time variations of $\mathrm{H}$ at TRD, ABG, TRD-ABG and Sq H at TRD following the SC at $2136 \mathrm{hr}$ on 26 June 1998.

time $(\mathrm{H}-\mathrm{Sq} \mathrm{H})$ fields at TRD and ABG were positive. There were no corresponding variations in solar wind speed or of density. Around $0600 \mathrm{hr}$ IMF-B $\mathrm{B}_{\mathrm{z}}$ turned southward causing a rapid decrease of Dst index reaching a minimum value at $0930 \mathrm{hr}$. $\mathrm{H}$ field decreased rapidly at ABG and more so at TRD reaching the minimum at $1030 \mathrm{hr}$. The $\Delta \mathrm{H}$ (TRDABG) showed significant decrease between 0600 and 1300 $\mathrm{hr}$, the minimum was at the time close to the maximum of mean $\mathrm{Sq}(\mathrm{H})$ field.

Thus the abnormal decrease of $\mathrm{H}$ field at any electrojet observatory during a magnetic storm occurs during the period of negative $\mathrm{IMF} \mathrm{B}_{\mathrm{z}}$ but the maximum effect is seen at the time of the maximum normal electrojet current.

2.3.2 Magnetic storm of 22-23 October 1981 In Fig. 8 are shown the variations of solar wind speed and density, IMF-B and $\mathrm{B}_{\mathrm{z}}$, Dst index and storm time $\Delta \mathrm{H}$ at TRD, ABG and TRD-ABG during magnetic storms following SC at $1025 \mathrm{hr}$ on 22 October 1981. The SC was associated with a very large increase of both the density and speed of the solar wind and with a significant increase of IMF B component. It was followed by a significant increase of Dst index for next four hours. The main phase started with the southward turning of $B_{z}$ reaching a minimum of $-20 \mathrm{nT}$ at 2030 hr, but the minimum Dst occurred few hours later. The main phase was associated with a large decrease of $\Delta \mathrm{H}(-240$ 


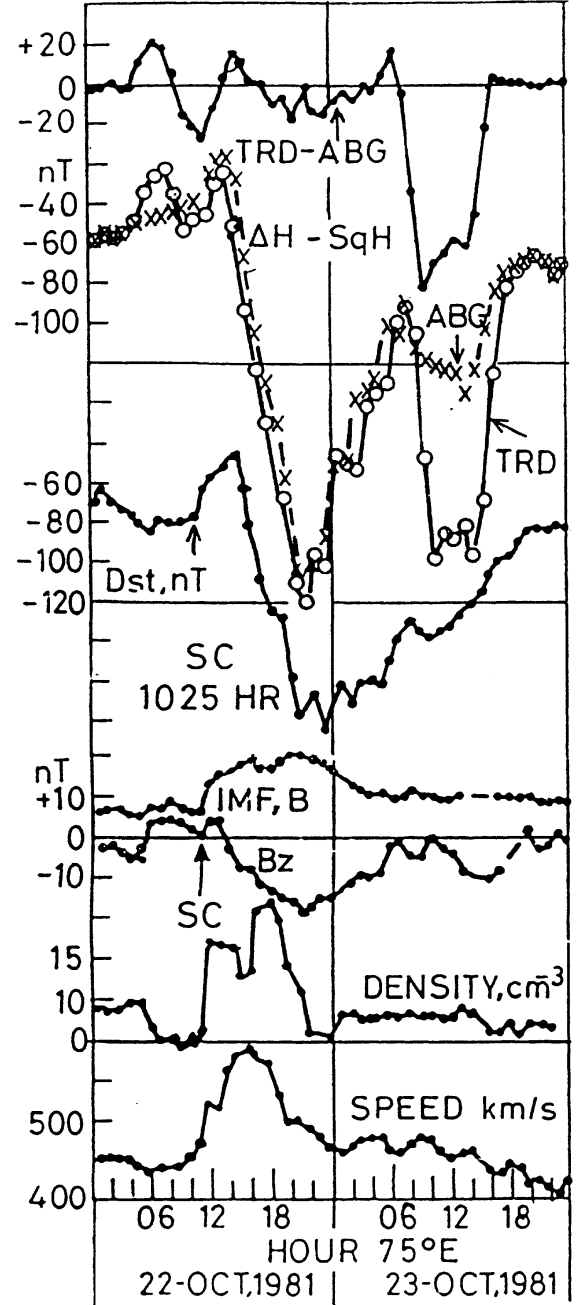

Fig. 8. Variation of solar wind parameters, density, speed, IMF $B$ and $B_{z}$, Dst index, storm time effects in $\mathrm{H}$ at different stations and Dst $(\mathrm{H})$ at TRD minus Dst $(\mathrm{H})$ at $\mathrm{ABG}$ on 22 and 23 October 1981 associated with the storm with SC at 1055 on 22 October 1981.

nT) at both TRD and ABG. With the recovery of Dst, the $\triangle \mathrm{H}$ at TRD and $\mathrm{ABG}$ also started increasing till an increase of southward $B_{z}$ as well as Dst around $0930 \mathrm{hr}$. This was followed by a very large decrease of $\mathrm{H}$ at TRD by about $100 \mathrm{nT}$. This abnormal decrease of the electrojet occurred well after the recovery of Dst had started but was associated with increase of southward IMF $B_{z}$ at a time corresponding to midday hours for Indian stations.

2.3.3 Magnetic storm of 19 October 1982 Figure 9 shows the variations of solar wind and ground magnetic field variations following a SC storm at $0052 \mathrm{hr}$ on 19 October 1982. The SC was associated with a significant rise of solar wind speed and density but IMF $B_{z}$ was small and constant for many hours before as well as till seven hours after SC. IMF $B_{z}$ turned southward $0830 \mathrm{hr}$ and remained practically constant at a value of $-20 \mathrm{nT}$ for next 12 hours, and gradually recovered to around zero level. The Dst index showed sharp decrease at $0630 \mathrm{hr}$ to $0830 \mathrm{hr}$ and a very slow and steady decrease reaching a value of $-120 \mathrm{nT}$ by $1830 \mathrm{hr}$, followed by a slow recovery. The $\Delta \mathrm{H}$ at TRD and ABG showed a very rapid decrease. The $\Delta H$ (TRD-ABG) decreased by about $100 \mathrm{nT}$ in one hour. Thus there was a

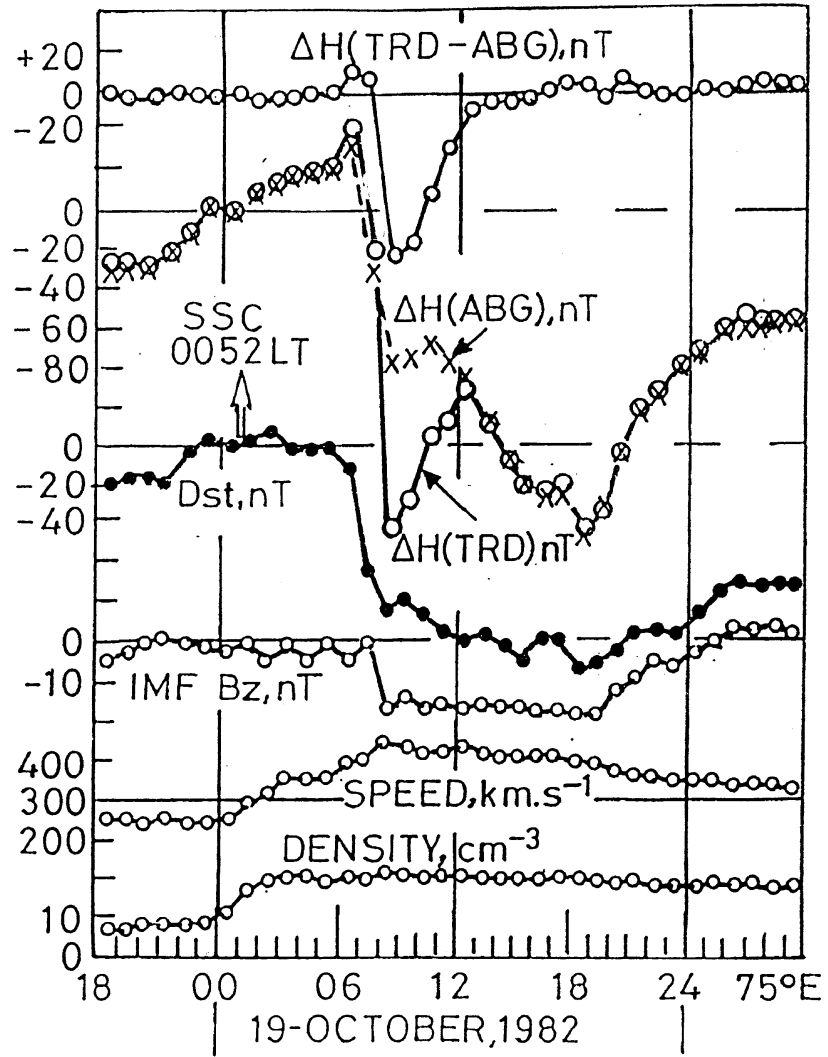

Fig. 9. Variations of solar wind speed and density, IMF $\mathrm{B}_{\mathrm{z}}$, Dst index, storm time $\triangle \mathrm{H}$ at TRD, ABG and TRD-ABG following a SC storm at $0052 \mathrm{hr}$ on 19 October 1982.

strong CEJ in the forenoon hours associated with the main phase of the storm. There were rapid decreases at $\Delta \mathrm{H}$ at TRD and ABG after $1200 \mathrm{hr}$ reaching a minimum around the time of minimum Dst, but the magnitudes of the $\Delta H$ were almost the same at TRD and ABG. Thus a very large abnormal decrease of $\Delta \mathrm{H}$ at the electrojet station can occur when IMF $B_{z}$ is not fluctuating but is strongly southward.

2.3.4 Magnetic storm of 20 February 1992 We have earlier (Fig. 4) described the storm time variations of $\mathrm{H}$ at all Indian stations for this storm. Here, are discussed the solar wind and IMF parameters associated with the storm. The solar wind density and speed, IMF-B and $\mathrm{B}_{\mathrm{z}}, \mathrm{AE}$ and Dst indices and $\triangle \mathrm{H}$ at TRD, ABG and TRD-ABG on 20 and 21 February 1992 are shown in Fig. 10. The SC was the result of a large increase of solar wind density and speed as well as of the IMF-B. The storm main phase started almost after the $\mathrm{SC}$ but the IMF $\mathrm{B}_{\mathrm{z}}$ data were not complete during the period. The IMF $B_{Z}$ was strongly southward during the period $1800 \mathrm{hr}$ on 21 February 1992. The Dst showed a minimum of $-150 \mathrm{nT}$ around midnight of 20-21 February, started rapid recovery thereafter, but again showed a large decrease around midday of 21 February. The AE index did not show any significant increase during these two days. The midnight minimum of Dst was associated by large decrease of $\mathrm{H}$ at TRD and $\mathrm{ABG}$ of similar magnitude. The midday decrease of $\mathrm{H}$ during the midday hours was associated with a much larger decrease at TRD than at ABG. It can be seen that the abnormal decrease of $\mathrm{H}$ field at the electrojet station was not associated with any, corresponding changes of 


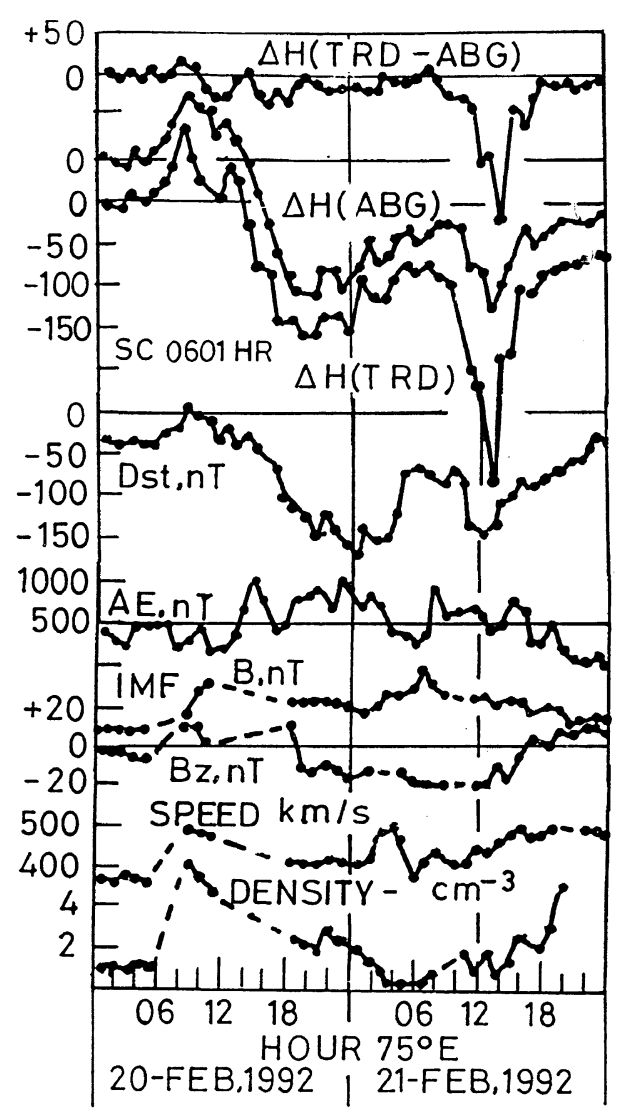

Fig. 10. Variations of solar wind speed and density, IMF $B$ and $B_{z}, A E$ and Dst indices, $(\mathrm{H}-\mathrm{Sq} \mathrm{H})$ at TRD, ABG and TRD-ABG during the storm following a SC at $0601 \mathrm{hr}$ on 20 February 1992.

solar wind on IMF parameters but was preceded by a long persistent period of southward IMF $\mathrm{B}_{\mathrm{Z}}$.

2.3.5 Magnetic storm of 8-9 July 1958 Next we like to investigate whether the abovementioned storm time features of the equatorial electrojet at stations in India exist at other longitudes too. In Fig. 11 are shown the storm time variations of $\mathrm{H}$ field at all the available equatorial electrojet stations during the July 1958 storm. The SC had occurred at 0748 UT on 8 July 1958, the main phase decrease started at $1530 \mathrm{UT}$ and a minimum value of $-320 \mathrm{nT}$ was recorded between 20 and 24 UT on 8 July. Data for the daytime are indicated by open circles and for the nighttime indicated by full circles. It can be seen that when the minimum Dst had occurred it was midnight at AAE and TRD, close to sunrise at KOR, midday at JAR and near sunset at HUA. The minimum $\Delta H$ around these hours were of the same order at all stations except at JAR where much deeper depression was observed. It is to be noted that during the recovery phase of the storm moderate depressions of $\Delta \mathrm{H}$ were noticed at AAE and TRD during local midday hours.

\subsection{Equatorial electrojet current at different longitude sectors}

It is to be concluded that the westward electric field during the magnetic storms continues for many hours up to even 24 hours if the IMF $B_{z}$ stays southward during the corresponding long period of time. The negative values of $\Delta \mathrm{H}$ move over the local midday longitude sector as the Sun progresses westward.

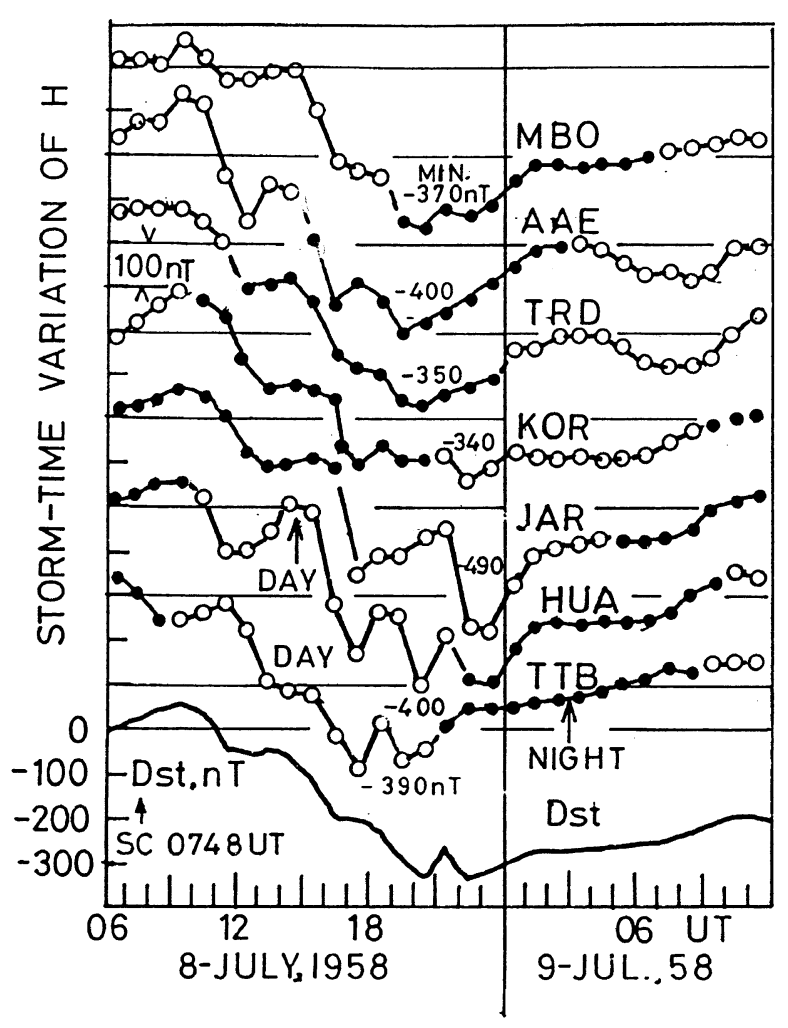

Fig. 11. Variations of solar wind speed and density, IMF $B$ and $B_{z}, A E$ and Dst indices, $(\mathrm{H}-\mathrm{Sq} \mathrm{H})$ at TRD, ABG and TRD-ABG during the storm following a SC at $0601 \mathrm{hr}$ on 20 February 1992.Storm time variations of $\mathrm{H}$ field at all available equatorial electrojet stations during the magnetic storm starting at 0748 UT on 8 July 1958.

2.4.1 Effect of sudden northward turning of IMF $B_{\mathrm{Z}}$ during the magnetic storm of 16 October 1970. We next present in Fig. 12 the solar wind and ground magnetic field data for a magnetic storm in which besides a slow increase of the ring current, an event of sudden change of the IMF latitude had occurred from consistent $90^{\circ} \mathrm{S}$ to a consistent $90^{\circ} \mathrm{N}$ directions. Then the effects of slow period of a day to a faster period of an hour changes of the IMF $B_{z}$ could be studied. A SC had occurred at 0917 UT on 16 October 1970 associated with a large sudden increase of IMF B field. While IMF B remained high and practically constant for the whole day, the latitude $(\theta)$ turned suddenly from northward to southward and then to northward. The initial phase of the storm started at 1230 UT and the minimum Dst was $-80 \mathrm{nT}$ at $1930 \mathrm{UT}$. A large change of latitude to southward at 1730 UT was accompanied with a large positive impulse of $\mathrm{H}$ at HUA and a later change of $(\theta)$ from $-90^{\circ}$ to $+90^{\circ}$ at $1830 \mathrm{UT}$ caused a very large decrease of $\mathrm{H}$ at Huancayo of a magnitude greater than $300 \mathrm{nT}$ for a period of two hours. This event was associated with the reversal of vertical $\mathrm{F}$ region drifts at Jicamarca from normally upward direction to a downward direction. The negative value of $\Delta \mathrm{H}$ (HUA-FUQ) was associated with the disappearance of Esq at Huancayo suggesting a strong westward ionospheric electric field.

Next we examine whether the large decrease of $\Delta \mathrm{H}$ during the period of northward turning of IMF $B_{z}$ was confined to the equatorial electrojet station only or as apparent 

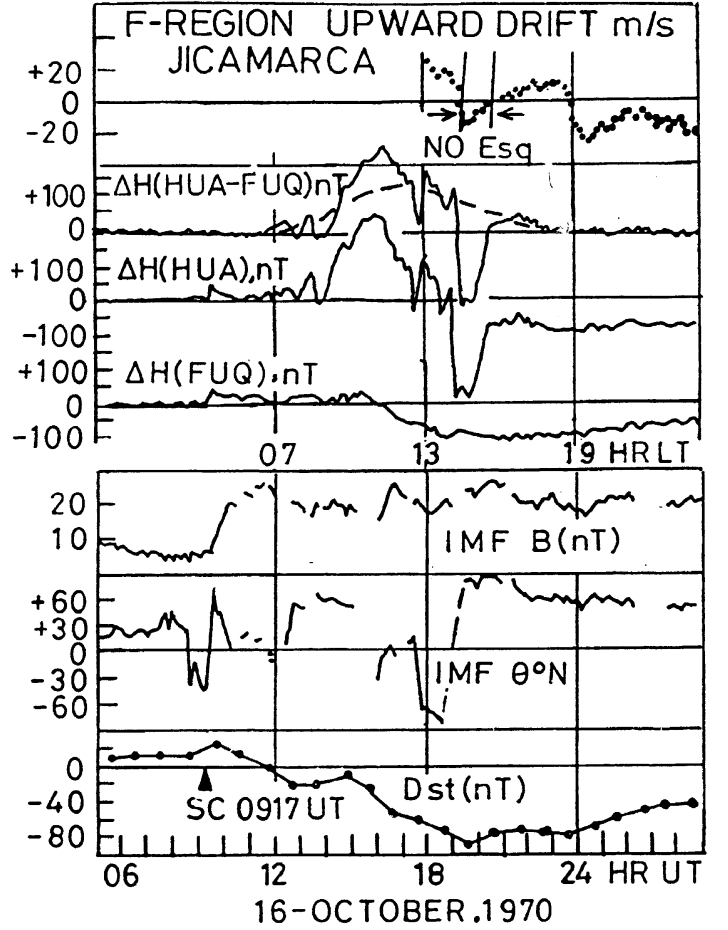

Fig. 12. Variation of Dst index, IMF B and IMF- $\mathrm{B}_{\mathrm{z}}$ components, $\Delta \mathrm{H}$ at Huancayo and Fuquene and $\mathrm{F}$ region drift velocity at Jicamarca following a SC storm at 0717 UT on 16 October 1970.

at other equatorial or low latitude stations. In Fig. 13 are shown the storm time variations of $\mathrm{H}$ at stations in American longitudes north and south of Huancayo as well as at MBO, AAE, TRD and ABG. It is to be noticed that large decrease of $\Delta \mathrm{H}$ at Huancayo at $1930 \mathrm{UT}$ is an additional decrease superposed over the decrease due to the disturbance Ring Current. Such large decrease was not observed at any other stations in American longitude sector or at any equatorial electrojet station in other longitude sectors. It is so because Huancayo was only electrojet station operating at close to the latitudes of local midday.

\section{Discussions and Conclusions}

Existence of large-scale electric fields in magnetosphere have been reviewed by Obayashi and Nishida (1968) and Stern (1977). The mechanisms for these fields can be classified into three types. (1) The polarization of the ambient plasma in the vicinity of the magnetopause caused by the frictional force exerted by solar wind (Axford and Hines 1961). As the solar wind flows past the magnetosphere, it would exert frictional force on the wings of the magnetosphere. This frictional force causes charge separation and the polarization charge is accumulated at the inner edge of the boundary region. (2) The polarization of energetic particles caused by the differential motion of particles (Chamberlein, 1961; Kern, 1961; Fejer, 1961). The charged particles from the sun carried by the solar wind while entering the Earths magnetic field are bent by the Lorentz force $F=q(V \times B)$ where $q$ is the charge of the particle, $V$ its velocity and $B$ the earth's dipole field. (3) The penetration of the interplanetary electric field into the magnetosphere associated with the bulk motion of the solar wind.

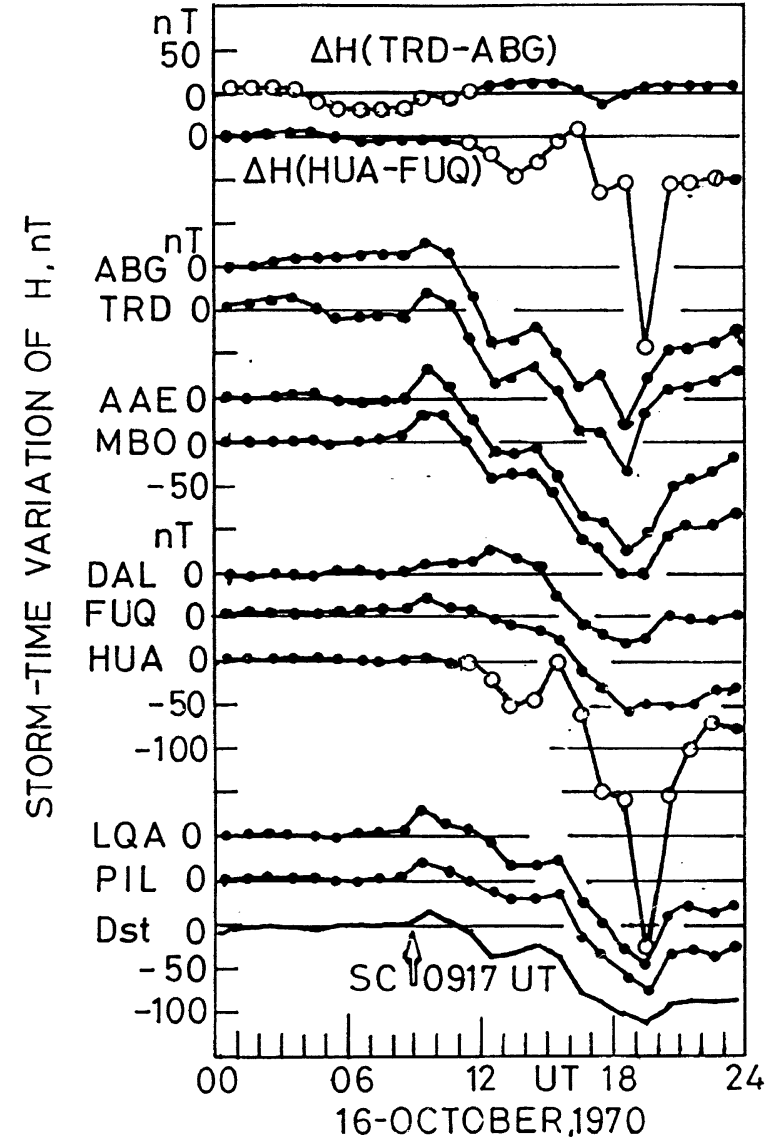

Fig. 13. Storm time variations of H field on 16 October 1970 at Huancayo compared with corresponding variations at mid latitude stations in American longitude sector and with variations at electrojet stations along other longitude sectors.

The electric field $\mathrm{E}$ associated with the solar wind velocity $U$ moving across the interplanetary magnetic field $B$ is given by $E=-1 / C(U \times B)$. In the magnetosphere the electric conductivity along field lines is high. Hence large-scale electric field in the magnetosphere can be conveyed to the ionospheric level with little spatial attenuation. In the ionosphere the applied electric field drive the auroral currents. Rostoker and Falthammar (1967) found that the positive increment in the azimuthally magnetospheric electric field (enhancement of the southward directed interplanetary magnetic field) is strongly related to the initiation of the storm activity and that the establishment of a negative (or less positive) azimuthally electric field during the course of a storm is associated with the start of the recovery phase. They confirmed an earlier suggestion by Fairfield and Cahill (1966) that the initiation of storm activity is strongly associated with the southward movement of IMF B (corresponding to a positive movement of E). Rostoker and Falthammar (1967) suggested the second major parameter, as a cause of geomagnetic activity is the solar wind dynamic pressure. An increase of this quantity implies an increase in either the solar wind velocity, the number density of particles in the solar wind some combinations of variations in these parameters.

Akasofu et al. (1965) showed that the most intense part of the auroral electrojet (near the midnight meridian) returns 
across the polar cap, encircling a focus in this cap; the reminder departs from the afternoon sector and crosses the midnight meridian to complete its circuit by rejoining the main westward flow in the morning sector. Akasofu and Chapman (1963) have shown an excellent example of the sub storm between 1700-1800 UT on 29 September 1957. Strong westward auroral electrojet in the European sector had the return current to low and middle latitudes extending to as far as the late afternoon along the magnetic equator. An abnormally large positive bay of magnitude exceeding $500 \mathrm{nT}$ was recorded at Huancayo.

Besides the effect due to these distant currents, the equatorial electrojet is very sensitive to any electric field imposed on the equatorial latitudes from any source whatsoever, producing an additional ionospheric current range over the magnetic equator. This way the equatorial electrojet acts as a very sensitive filter for separating out electric field changes during any complex situations.

Nishida et al. (1968a) described the coherent fluctuations in $\mathrm{H}$ field from pole to the equator with a marked peak-topeak correspondence between them. Later, Nishida (1968b) found a high degree of correlation between these fluctuations and the southward component of the interplanetary magnetic field. Onwumechilli et al. (1973) showed that the fluctuations of $\mathrm{H}$ field of Huancayo are very well correlated with simultaneous fluctuations of $(\mathrm{H}$ at high latitude stations Eskdalemuir, Kiruna and Leirvogur. Somayajulu et al. (1989) showed an interesting comparison between the position of the polar cusp during a magnetic storm with the mean Doppler shift of backscatter echoes at Thumba. A decrease (or increase) in the mean latitude of the polar cusp region was completely in phase with the decrease or increase of the storm-time electric field in the equatorial region.

Kikuchi et al. (1996) have described the quasi-periodic DP2 magnetic fluctuations (period of 30-40 min) appearing coherently at auroral and equatorial latitudes during the day based on the high resolution magnetometer data recorded at the International Monitor of Auroral Geomagnetic Effects (IMAGE) stations in Scandinavia and at the Brazilian and African equatorial stations. Correlation between DP2 fluctuations at both latitudes was excellent (correlation coefficient of 0.9) with no time shift within the resolution of $25 \mathrm{sec}$. The DP2 fluctuations exhibited a strong decrease in magnitude with decreasing latitude, however, it was enhanced considerably at the dip equator with an amplitude comparable to that at the subauroral latitude. It was suggested that the ionospheric current generated by magnetospheric electric field at high latitudes extend to the equatorial ionosphere almost instantaneously. No source of these electric field generated in the magnetosphere was discussed.

Kikuchi et al. (2000) described another example of the evolution of the electric field in the dayside auroral and equatorial ionosphere during a substorm on July 16, 1995. A southward turning of the IMF detected by WIND caused enhancements in the auroral electrojet intensity in the morning and afternoon sectors as observed by the IMAGE and CANOPUS magnetometer chains. Coherent magnetic variations were observed at subauroral to equatorial latitudes simultaneously with the auroral magnetic variations with a temporal resolution of $10 \mathrm{~s}$. During the recovery phase, a rapid decrease of the electric field was caused by northward turning of the IMF. This decrease of the magnetic field resembled with the counter equatorial electrojet event in the afternoon sector.

Tsunomura (1999) developed a model of the global twodimensional ionospheric layer conductivity considering the effect of meridional current systems on the equivalent ionospheric conductivity. He discussed the latitudinal profile of the DP2-type magnetic variation in the daytime, changing the rate of shielding for the dawn to duck electric field due to the region 2 current. He showed that the equivalent enhancement would not appear when the ratio of region 2 to region 1 current exceeds 0.5 .

The basic polarity of global electric field in polar regions during southward IMF-B $\mathrm{z}_{\mathrm{z}}$ period is dawn to dusk (Heppner, 1997; Volland, 1978; Sojka, 1980; Foster, 1983). The polar electric field are shown to have opposite polarity at equatorial latitudes in the same hemisphere (longitude sector) and of similar polarity on the equatorial latitudes of the other hemisphere. Thus the polar electric field has a global structure and extends to both dayside as well as the nightside hemispheres. A reduction of dawn to dusk electric field in the polar region affects apparent westward electric field in the dayside electrojet region.

The present analysis clearly indicate the two types of interaction of solar wind with the earth's magnetosphere producing electric field which affect the ionospheric current at all latitudes but most perceptible changes occur at auroral and equatorial latitudes due to abnormal ionospheric conductivities in these regions.

First, the slow variation of IMF-B $\mathrm{B}_{\mathrm{z}}$ of the period of few hours or of day to day variation cause significant variations of the solar diurnal variations at polar and equatorial latitudes. The increasing magnitude of IMF-B $\mathrm{B}_{\mathrm{z}}$ causes an increase of the electric field at low latitudes and increases the equatorial electrojet. The decrease of $\mathrm{IMF}_{\mathrm{B}} \mathrm{B}_{\mathrm{z}}$ or the more southerly component of $\mathrm{B}_{\mathrm{z}}$ imposes a anti-Sq electric field at lo latitude ionosphere.

The second process involves rapid changes of $I M F-B_{Z}$ with a period of the order of an hour to few seconds. These sudden changes of $B_{z}$ generate a negative $B_{z}$ electric field at the magnetopause region, which is transmitted immediately to the ionosphere at auroral and to the equatorial latitudes. An increase of northward $B_{z}$ causes an anti Sq electric field at low latitudes. During the periods when scalar IMF-B field is high and steady it is the latitude $(\theta)$ of the IMF which is related to the changes of $\mathrm{H}$ field at equatorial latitudes (Alex et al., 1986).

During the magnetic storm period when large slow as well as fast changes in interplanetary $\mathrm{B}_{\mathrm{z}}$ components occur, both the abovementioned processes of generating ionospheric electric fields are operative. The slow, on steady large southward $\mathrm{B}_{\mathrm{z}}$ besides generating the disturbance ring current produces a westward electric in the dayside of the ionosphere causing an additional decrease of the $\mathrm{H}$ field at equatorial latitudes. These changes are largest at station closest to the magnetic equator and closest to the midday longitude sector.

Sometimes large and sudden changes in $\mathrm{IMF}_{\mathrm{z}} \mathrm{B}_{\mathrm{z}}$ occur during the main phase or in the recovery phase of the mag- 
netic storm. These changes produce the second type of electric field $\left(-v e \mathrm{~B}_{\mathrm{z}}\right)$ imposed on the low latitude ionosphere. This can cause abnormally large decrease of the $\mathrm{H}$ field at electrojet stations larger than that produced by any ring current disturbance. These large changes are not recognizable at stations outside the equatorial electrojet belt.

It is suggested that a close study of high resolution solar wind data with the equatorial electrojet magnetic and ionospheric data, would lead to better understanding of the association of equatorial electrojet with solar wind.

\section{Conclusions}

1) The storm time variation of the $\mathrm{H}$ field at a low latitude station outside equatorial electrojet belt follows fairly well the corresponding variation of the equatorial ring current index Dst, for any local time of the day or the night.

2) The magnitude of minimum value of $\mathrm{H}$ field at a low latitude station during the magnetic storm, averaged over a large number of events shows a clear variation with the local time of the minimum Dst index. The average minimum $\mathrm{H}$ shows a maximum around dawn hours and a minimum around dusk hours.

3) The minimum value of $\mathrm{H}$ field at an electrojet station during a magnetic storm peak occurring during local night corresponds fairly well with the corresponding Dst index.

4) The minimum value of $\mathrm{H}$ field at any equatorial electrojet station during a magnetic storm occurring during local daytime shows a deep minimum around noon. This decrease is further deepest at a station close to the magnetic equator.

5) The magnitude of minimum value of $\mathrm{H}$ at an equatorial electrojet station averaged over a large number of magnetic storm events shows a dawn maximum a dusk minimum and a larger midday minimum.

6) The equatorial decrease of $\mathrm{H}$ field during daytime storms are shown to be associated with the imposition of a westward electric field over the normal Sq field at the ionospheric heights indicated by the absence of equatorial sporadic E layer and the absence of equatorial $\mathrm{F}_{2}$ layer fountain phenomenon.

7) This additional midday decrease of $\mathrm{H}$ at equatorial station is concurrent in time with the southward Interplanetary Magnetic Field and not necessarily with the decrease of Dst index.

8) The equatorial decrease of storm time $\mathrm{H}$ field during day time is associated with increased auroral current activities preferably with the westward current indicated by AL index.

Acknowledgments. The findings are the result of long and slow investigations during which the author was supported by the Council of Scientific and Industrial Research, New Delhi, Indian National Science Academy, New Delhi and Indian Space Research Organization, Banglore. He is indebted to Physical Research Laboratory for infrastructural support during the period. Thanks are also due to Prof. H. Chandra for discussions, suggestions and assistance during the preparation of the paper.

\section{References}

Akasofu, S. I. and S. Chapman, Magnetic storms: the simultaneous development of the main phase (DR) and of polar magnetic storm (DP), $J$. Geophys. Res., 68, 3158-3185, 1963.

Akasofu, S. I., S. Chapman, and C. I. Meng, The polar electrojet, J. Atmos. Terr. Phys., 27, 1275-1305, 1965.

Alex, S., A. R. Patil, and R. G. Rastogi, Equatorial counter electrojetsolution of some dilemma, Ind. J. Rad. Space Phys., 15, 114-118, 1986.

Axford, W. I. and C. O. Hines, A unifying theory of high latitudes geophysical phenomena and geomagnetic storms, Can.J. Phys., 39, 1433-1464, 1961.

Baker, W. G. and D. F. Martyn, Electric currents in the ionosphere Part I. the conductivity, Phil. Trans. Roy. Soc. Lond., A 246, 281-294, 1953.

Balsley, B. B., Electric fields in the equatorial ionosphere: a review of techniques and measurements, J. Atmosph. Terr. Phys., 35, 1035-1044, 1973.

Bartels, J. and H. F. Johnston, Geomagnetic tides in horizontal intensity at Huancayo, J. Geophys. Res., 45, 269-308, 1940.

Burlaga, L. F. and K. Ogilivie, Causes of sudden commencement and sudden impulses, J. Geophys. Res., 74, 2815-2825, 1960.

Carter, D. A., B. B. Balsley, and W. L. Ekerlund, V.H.F. Doppler radar observations of the African Equatorial Electrojet, J. Geophys. Res., 81, 2786-2794, 1976.

Chamberlain, J. W., Theory of auroral bombardment, Astrophys. J., 134, 401-424, 1961.

Chandra, H., R. K. Misra, and R. G. Rastogi, Equatorial ionospheric drift and the electrojet, Planet. Space Sci., 19, 1497-1503, 1971.

Chapman, S., The solar and lunar diurnal variation of the earth's magnetism, Phil. Trans Roy. Soc. Lond., A 218, 1-118, 1919.

Chapman, S., The equatorial electrojet as deduced from the abnormal current distribution above Huancayo and elsewhere, Arch. Meteorol. Geophys. Bioklimatol. Sec., A4, 368-390, 1951.

Cowling, T. G. and R. Borger, Electrical conductivity of the ionospheric D region, Nature, 162, 143, 1948.

Davis, T. N. and M. Sugiura, Auroral electrojet activity index AE and its universal time variations, J. Geophys. Res., 71, 785-801, 1966.

Deshpande, M. R. and R. G. Rastogi, Studies in variations in the electron drifts over the magnetic equator, J. Atmos. Terr. Phys., 30, 319-323, 1968.

Egedal, J., The magnetic diurnal variation of the horizontal force near the magnetic equator, Terr. Magn. Atmos. Electr., 52, 449-451, 1947.

Fairfield, D. H. and L. J. Cahill, Jr., Transition region magnetic field and polar magnetic disturbances, J. Geophys. Res., 71, 155-169, 1966.

Fambitakoye, O., R. G. Rastogi, J. Tabbagh, and P. Vila, Counter electrojet and Esq disappearance, J. Atmos. Terr. Phys., 35, 1119-1126, 1973.

Fejer, B. G., D. T. Farley, R. F. Woodman, and C. Calderon, Dependence of equatorial $\mathrm{F}$ region vertical drifts and season and solar cycle, $J$. Geophys. Res., 84, 5792, 5796, 1979.

Fejer, J. A., The effect of energetic trapped particles on magnetospheric motion and ionospheric currents, Can.J. Phys., 39, 1409, 1417, 1961.

Foster, J. C., An empirical electric field model derived from chatamika radar data, J. Geophys. Res., 88, 981-987, 1983.

Gouin, P. and P. N. Mayaud, A propos de l' existence possible d'un cortre electrojet aux latitudes magnetiques equatoriales, Ann. Geophys., 23, 41-47, 1967.

Heppner, J. P., Emperical model of high latitude electric field, J. Geophys. Res., 82, 1115-1125, 1977.

Kelley, M. C., C. Gonzales, E. S. Mozer, and R. F. Woodman, Conference Digest, 5th Int. Symp. On Equatorial Aeronomy, Towunsville, Australia Paper 8-3.

Kern, J. W., Solar stream distortion of the geomagnetic field and polar electrojet, J. Geophys. Res., 66, 1290-1292, 1961.

Kikuchi, T., H. Luhr, T. Kitamura, O. Saka, and K. Schlegel, Direct penetration of the polar electric field to the equator during a DP2 event as detected by the auroral and equatorial magnetogram chains and the EISCAT radar, J. Geophys. Res., 101, 17161-17173, 1996.

Kukuchi, T., M. Pinnock, R. Rodger, H. Luehr, H. Tachihara, M. Watanabe, N. Sato, and M. Ruohoniemi, Global evolution of a substorm-associated DP2 current system observed by superdarn and magnetometers, $A d v$. Space Res., 26, 121-124, 2000.

Misra, R. K., H. Chandra, and R. G. Rastogi, Solar cycle effects in the electron drifts over the magnetic equator, J. Geomag. Geoelectr., 23, 181-186, 1971.

Moos, N. A. F., Magnetic observations made at the government Observatory Bombay 1847 to 1905 and their discussions Part II. The phenomenon and its discussion, Bombay 1910. 
Nishida, A., Geomagnetic DP2 fluctuations and associated magnetospheric phenomena, J. Geophys. Res., 73, 1795-1803, 1968a.

Nishida, A., Coherence of DP2 fluctuations with interplanetary magnetic field variations, J. Geophys. Res., 73, 5549-5559, 1968b.

Obayashi, T. and A. Nishida, Large scale electric field in the magnetosphere, Space Sci. Rev., 8, 3-31, 1968.

Onwumechilli, A., K. Kawasaki, and S. I. Akasofu, Relationship between the equatorial electrojet and polar magnetic variations, Planet. Space Sci., 21, 1-16, 1973.

Patel, V. P. and H. Chandra, Ionospheric E-region drifts at Sibizmir during 1970-75, Ind. J. Rad. Space Phys., 11, 187, 1982.

Rastogi, R. G., Sudden disappearance of Esq and the reversal of the equatorial electric fields, Ann. Geophys., 28, 717-728, 1972.

Rastogi, R. G., Es-q layer at Huancayo during the March 1970 geomagnetic storm, Planet. Space Sci., 21, 197-203, 1973a.

Rastogi, R. G., The effect of polar magnetic substorms on the equatorial sporadic E., Proc. Ind. Acad. Sci., 78, 130-138, 1973b.

Rastogi, R. G., Westward equatorial electrojet during daytime hours, $J$. Geophys. Res., 79, 1503-1512, 1974.

Rastogi, R. G., On the simultaneous existence of eastward and westward flowing equatorial electrojet current, Proc. Ind. Acad. Sci., A 81, 80-92, 1975.

Rastogi, R. G., Coupling between equatorial and auroral ionospheres during polar sub-storms, Proc. Ind. Acad. Sci., 86A, 409-416, 1977.

Rastogi, R. G., The Equatorial Electrojet: Magnetic and Ionospheric Effects in Geomagnetism, edited by J. Jacobs, Academic Press Ltd., Vol. 3, pp. 461-525, 1989.

Rastogi, R. G., Geomagnetic storm effects at low latitudes, Ann. Geophysicae, 17, 438-441, 1999.

Rastogi, R. G., Westward electric field in the low latitude ionosphere during the main phase of the magnetic storms occurring around the local midday hours, National Academy Science Letters, 27(1,2), 69-74, 2004.

Rastogi, R. G. and H. Chandra, Interplanetary magnetic field and the equatorial ionosphere, J. Atmos. Terr. Phys., 36, 377-379, 1974.

Rastogi, R. G. and V. L. Patel, Effect of interplanetary magnetic field ionosphere over the magnetic equator, Proc. Ind. Acad. Sci., A82, 121141,1975

Rastogi, R. G. and A. R. Patil, Complex structure of equatorial electrojet currents, Currn. Sci., 85, 433-436, 1986.
Rastogi, R. G., H. Chandra, and S. C. Chakravarty, The disappearance of equatorial Es and the reversal of electrojet current, Proc. Ind. Acad. Sci., 73, 62-67, 1971a.

Rastogi, R. G., H. Chandra, and R. K. Misra, Effect of magnetic activity on electron drifts in the equatorial electrojet region, Nature (London), 233, 1315, 1971b.

Rastogi, R. G., H. Chandra, R. P. Sharma, and G. Rajaram, Ground based measurements of ionospheric phenomenon associated with equatorial electrojet, Ind. J. Rad. Space Phys., 1, 119-135, 1972.

Rastogi, R. G., B. G. Fejer, and R. F. Woodman, Sudden disappearance of VHF Doppler radar echoes from the equatorial E region irregularities, Ind. J. Rad. Space Phys., 6, 39-43, 1977.

Rostoker, G. and C. G. Falthammar, Relationship between charges in the interplanetary magnetic field and variation in the magnetic field in the Earth's surface, J. Geophys. Res., 72, 5855-5863, 1967.

Sojka, J. J., J. C. Joster, M. J. Raitt, and R. W. Schunk, High latitude connection: comparison of a simple model with incoherent scatter observations, J. Geophys. Res., 85, 703-709, 1980.

Somayajulu, V. V., C. A. Reddy, and K. S. Viswanathan, Simultaneous electric field changes in the equatorial electrojet in phase with polar cusp latitude changes during a magnetic storm, Geophys. Res. Lett., 12, 473-475, 1985.

Stern, D. P., Large scale electric field in the Earth's magnetosphere, Rev. Geophys. Space. Phys., 15, 186-194, 1977.

Stewart, B., Terrestrial Magnetism, in Encyclopedia Brittanica, 9th edition, 1882.

Sugiura, M., Hourly values of eqauatorial Dst for the IGY, Annals of the International Geophysical Year, 35, 4-45, 1964.

Sugiura, M. and S. Chapman, The average morphology of geomagnetic storm with sudden commencement, Abh. Akad. Wiss. Geottingen. Math. Phys. Klasse Sonder heft, Nr. 4, 1-53, 1960.

Tsumomura, S., Numerical analysis of global ionospheric current system including the effect of equatorial enhancement, Ann. Geophys., 17, 692706, 1999.

Volland, H., A model of magnetospheric electric convection field, J. Geophys. Res., 83, 2695-2699, 1978.

R. G. Rastogi (e-mail: profrgrastogi@yahoo.com) 